\title{
Türkiye için yeni bir istilacı yabancı bitki kaydı: Alternanthera sessilis (Amaranthaceae)
}

\author{
Yelda GÜZEL ${ }^{1}$
}

\author{
ABSTRACT \\ A new invasive weed record for Turkey: Alternanthera sessilis \\ (Amaranthaceae)
}

\begin{abstract}
A tropical weed, Alternanthera sessilis (L.) R. Br. ex DC which is defined as invasive plant by organisations like CABI (Invasive Species Compendium) and EPPO (European and Mediterranean Plant Protection Organization) was encountered at the banks of the Asi River (Hatay) as three populations. So, it was determined that the species have entered to our country also after the countries like Iran, Iraq, Jordan and Israel. The species was introduced with taxonomical and morphological features herein. Its ecological impact evaluated with potential risks also.
\end{abstract}

Keywords: Invasive weed, new record, Alternanthera sessilis, Amaranthaceae

\section{ÖZ}

CABI (Invasive Species Compendium) ve EPPO (European and Mediterranean Plant Protection Organization) gibi organizasyonlar tarafindan istilac1 yabanc1 ot olarak tanımlanan tropikal kökenli Alternanthera sessilis, Asi Nehri (Hatay) kıyllarında üç popülasyonda tespit edilmiştir. Böylece İran, Irak, Ürdün ve İsrail gibi ülkelerden sonra ülkemize de giriş yapmış olduğu belirlenmiştir. Bu makalede tür taksonomik ve morfolojik özellikleriyle tanıtılmış, ekolojik önemi, taşıdığı risk ile beraber değerlendirilmiştir.

Anahtar kelimeler: İstilacı yabancı ot, yeni kayıt, Alternanthera sessilis, Amaranthaceae

\section{GíRIŞ̧}

Gelişen teknolojinin ulaşımı ve ticareti kolaylaştırmasıyla coğrafi sınırlar istilacı yabancı türler için engel olmaktan çıkmıştır. Doğal yaşam alanları haricindeki bölgelere, insan aktiviteleriyle doğrudan ya da dolaylı olarak taşınan istilacı

\footnotetext{
${ }^{1}$ Mustafa Kemal Üniversitesi, Fen Edebiyat Fakültesi, Biyoloji Bölümü, 31040, Antakya, Hatay Sorumlu yazar (Corresponding author) e-mail: yeldaguzel@gmail.com Alınış (Received): 28.11.2016, Kabul ediliş (Accepted): 27.02.2017
} 
yabancı bitkiler biyoçeşitlilik açısından, önemi giderek artan bir sorun haline gelmişlerdir. İstilacı yabancı bitkilerin biyoçeşitliliğe olduğu kadar ekonomiye de öngörülemez zararları vardır. $\mathrm{Bu}$ nedenle söz konusu bitkileri tespit etmek ve tanımak, mücadele edebilmek açısından şarttır (Önen 2015). Önen ve ark. (2015)'e göre, istilacı bitkilerin erken tanısı ve takibinin ilk üç aşamasını; "sürvey ve gözlemler sayesinde erken tespit", "teşhis ve verilerin analizi" ile "raporlama" oluşturur. Bu makalenin amac1, Türkiye'ye giriş yapmış olduğunu tespit ettiğimiz ve Alternanthera sessilis (L.) R. Br. ex DC olarak teşhis ettiğimiz bitki ile ilgili verileri raporlamak, böylece tanı ve takibin söz konusu ilk üç aşamasını gerçekleştirmektir.

Alternanthera Forssk., çeşitlenme merkezi Güney Amerika olan, Amaranthaceae familyasına mensup bir neotropikal cinsdir (Iamonico and Sánchez-Del Pino 2016). Cinse mensup, A. sessilis, habitat olarak sulak alanlar başta olmak üzere, her türlü nemli habitatı, yol kenarlarını ve tarlaları tercih eden ancak ileri derecede kurak koşullara da dirençli olan çok yıllık, otsu bir türdür. 0-2000 m arası yükseltilerde bulunabilir (Gunasekera 2008). Dolayısıyla ekolojik toleransı son derece yüksektir. "Invasive Species Compendium (CABI)" (Anonymous 2015), "European and Mediterranean Plant Protection Organization (EPPO)" (Anonymous 2016a) ve "Global Invasive Species Database (GISD)" (Anonymous 2005) gibi organizasyonlar tarafindan, istilacı zararlı ot olarak ele alınır. Tanveer et al. (2013)'e göre, A. philoxeroides ve A. sessilis türlerinin yabanc1 ot olarak yayıldıkları çeltik ve soya fasulyesi tarlalarında, \%19-60'a varan verim kayıpları görülebilmektedir. Bununla birlikte, bazı Güneydoğu Asya ve Afrika ülkelerinde $A$. sessilis sebze ya da trbbi bitki olarak yararlanılan faydalı bir bitki olarak da değerlendirilir (Gunasekera 2008). Türün faydalı bitki olarak kullanılabilme potansiyeline karşın, Alternanthera cinsi üyeleri özellikle sulak alanlarda istilacı karakter gösterdiklerinden ve sulak alan ekosistemleri dünyanın en hassas ve tehdide açık ekosistemlerinden olduklarından, genel eğilim bu türleri yayılmacı zararlı ot olarak değerlendirmek yönündedir (Iamonico and Sánchez-Del Pino 2016).

EPPO (Anonymous 2016a) verilerine göre İran, Irak, İsrail, Ürdün, İtalya ve Rusya'ya yayılmış olan $A$. sessilis, her ne kadar yüksek bir ekolojik tehdit arz etmese de, yayılışını diğer Akdeniz ülkelerine doğru genişletmesi beklendiğinden takip edilmesi önerilir.

$\mathrm{Bu}$ makalede, Türkiye sınırlarına girmiş bulunduğunu tespit ettiğimiz tür, taksonomik ve morfolojik özellikleriyle tanıtılmış, ekolojik önemi, taşıdığı risk ile beraber değerlendirilmiştir. 


\section{MATERYAL VE METOT}

Bitki ilk defa, Ağustos 2016'da, tıp doktoru, amatör botanikçi ve kuş gözlemcisi Dr. Ali Atahan'ın Asi nehri kıyılarında çekmiş olduğu çeşitli bitki fotoğrafları arasından dikkati çekmiştir. Detaylı arazi çalışmalarıyla bitkiyi habitatında görüp örnek topladıktan sonra Amaranthaceae familyasının Türkiye'de bulunmayan bir cinsine mensup olduğu tespit edilmiştir. Bunun üzerine, familya taksonomisi ile ilgili literatür araştırılmıştır (Anonymous 2016b, Henao 2009, Iamonico and Sánchez-Del Pino 2016). Popülasyonların A. sessilis türüne mensup olduğu ve cinsin yayılıcı zararlı ot özelliğine sahip olduğu anlaşıldıktan sonra, türe dair temel taksonomik yayınlar (De Candolle 1813, Linné 1753) ve yayılıcı zararlı otlar ile ilgili CABI (Anonymous 2015), EPPO (Anonymous 2016a) ve GISD (Anonymous 2005) gibi kaynaklar da incelenmiştir. Arazide $\mathrm{m}^{2}$ başına birey sayısı sayılarak popülasyon yoğunluğu bitki $/ \mathrm{m}^{2}$ formülüne (Odum 1971) göre hesaplanmıştır.

Gerek türün teşhisi için, gerekse teşhisten sonra morfolojik özelliklerine dair detaylı veri elde etmek için bitki örnekleri Olympus BX50 trinoküler mikroskop ile incelenmiştir. Herbaryum örneği haline getirilen bitki örnekleri MKÜ (Mustafa Kemal Üniversitesi) ve ANK (Ankara Üniversitesi) herbaryumlarında saklanmışırı.

\section{SONUÇLAR}

Alternanthera sessilis (L.) R. Br. ex DC. Catalogus Plantarum Horti Botanici Monspeliensis, 77, 1813:

Çok yıllık, nadiren tek yıllık, dik ya da sürünücü gövdeli otsu bitki. Gövde yeşilmorumsu, nod bölgelerinde köklenme mevcut. Bitki genellikle tüysüz, bazen yer yer seyrek tüy örtüsü görülebilir. Yapraklar lineer-lanseolat'tan oblong-obovat'a değişken şekillerde, 2-11 x 0,5-2 cm boyutlarında. Yaprak ayasının tepesi kısa akuminat, tabanı kuneat-attenuat. Petiol yok ya da 5 mm'ye kadar, kısa. Çiçek durumu yaprak koltuklarında sessil, yaklaşık $5 \mathrm{~mm}$ çapında ve küresel. Bazen, özellikle meyve döneminde, küresel çiçek durumu hafif uzama gösterir. Brakteler zars1, beyaz, deltoid-ovat, belirgin, tek ortadamarlı, yaklaşık $1 \mathrm{~mm}$. Kaliks/korolla farklılaşması yok. Tepaller 5 tane, hemen hemen aynı boyda, 1,5-2 $\mathrm{mm}$ beyaz, mukronat, belirgin tek ortadamarl. Stamenler 5 adet. İkisi antersiz. Ovaryum yass1, yuvarlak. Meyve obkordat veya kordat-orbikulat, 2-2,5 mm uzunluğunda, yassi. Tohum disk şeklinde yaklaşık $1 \mathrm{~mm}$ çapında (Şekil 1, Şekil 2, Şekil 3 ve Şekil 4). 
Türkiye için yeni bir istilacı yabancı bitki kayıdı: Alternanthera sessilis (Amaranthaceae)

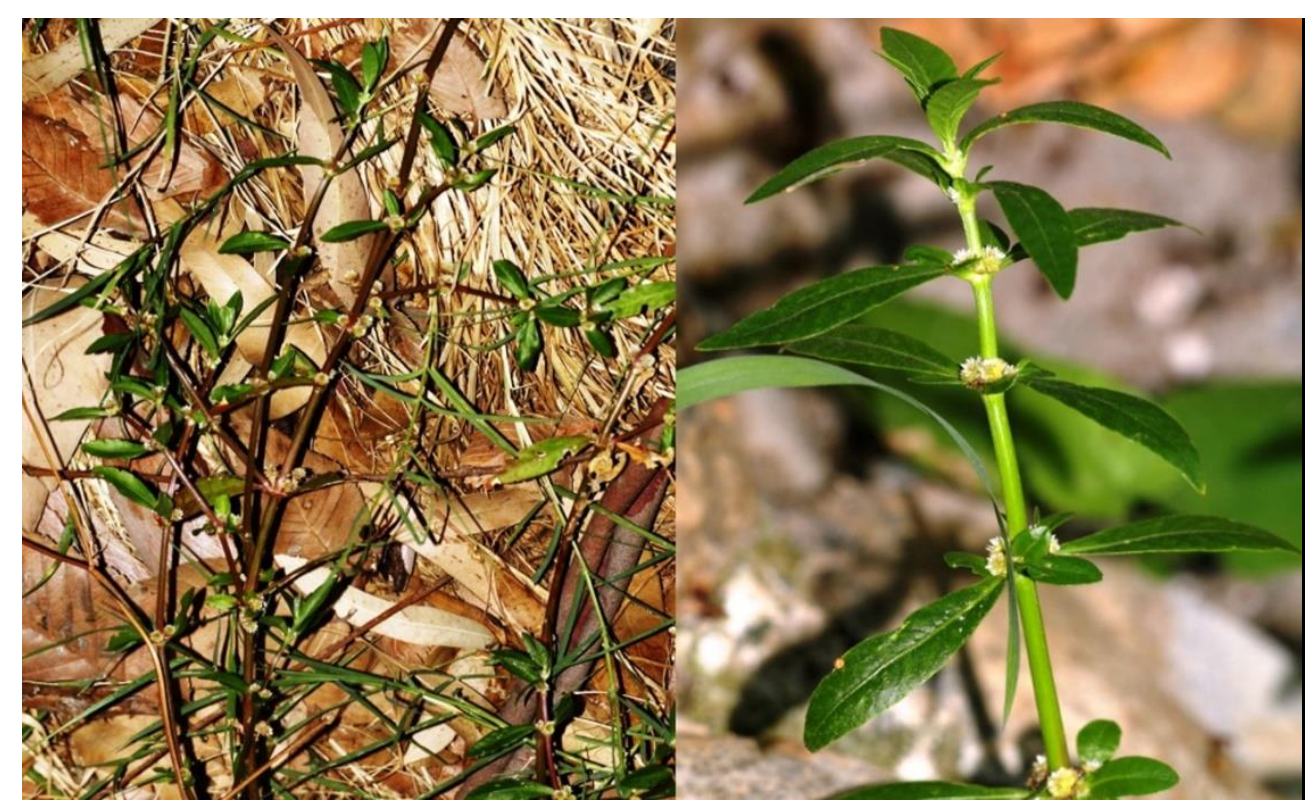

Şekil 1. Alternanthera sessilis genel görünüm.

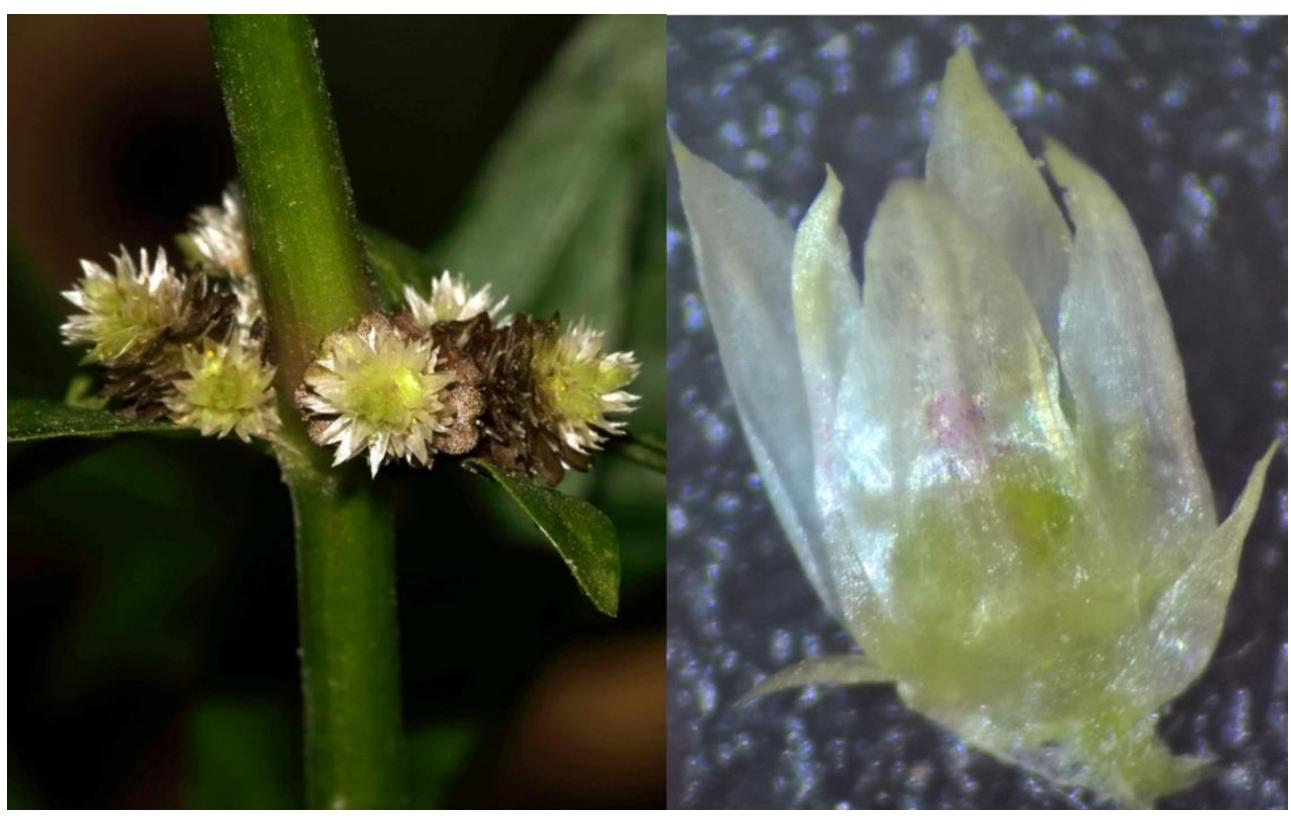

Şekil 2. Sessil çiçek durumu (solda) ve bir çiçeğin yakından görünümü. Brakteler ve 5 tepal (sağda). 


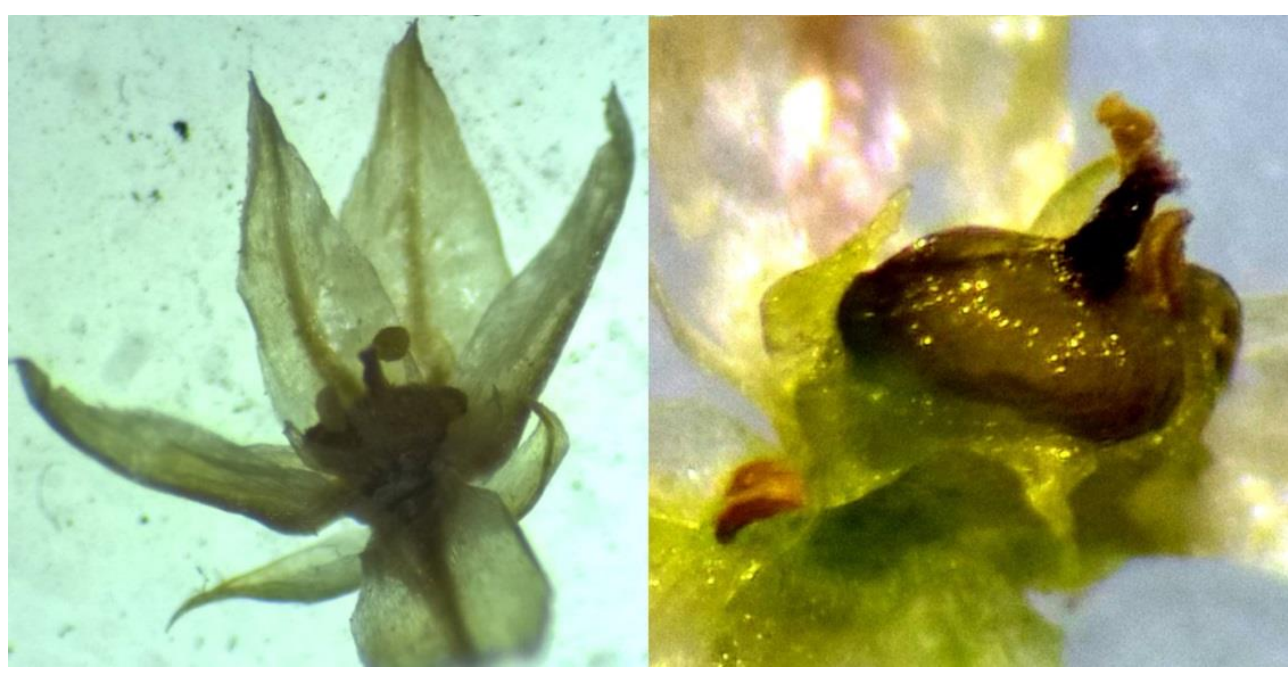

Şekil 3. Çiçeğin yakından görünümü. Tepallerdeki belirgin tek orta damar (solda); ikisi antersiz 5 stamen ve ovaryum (sağda).

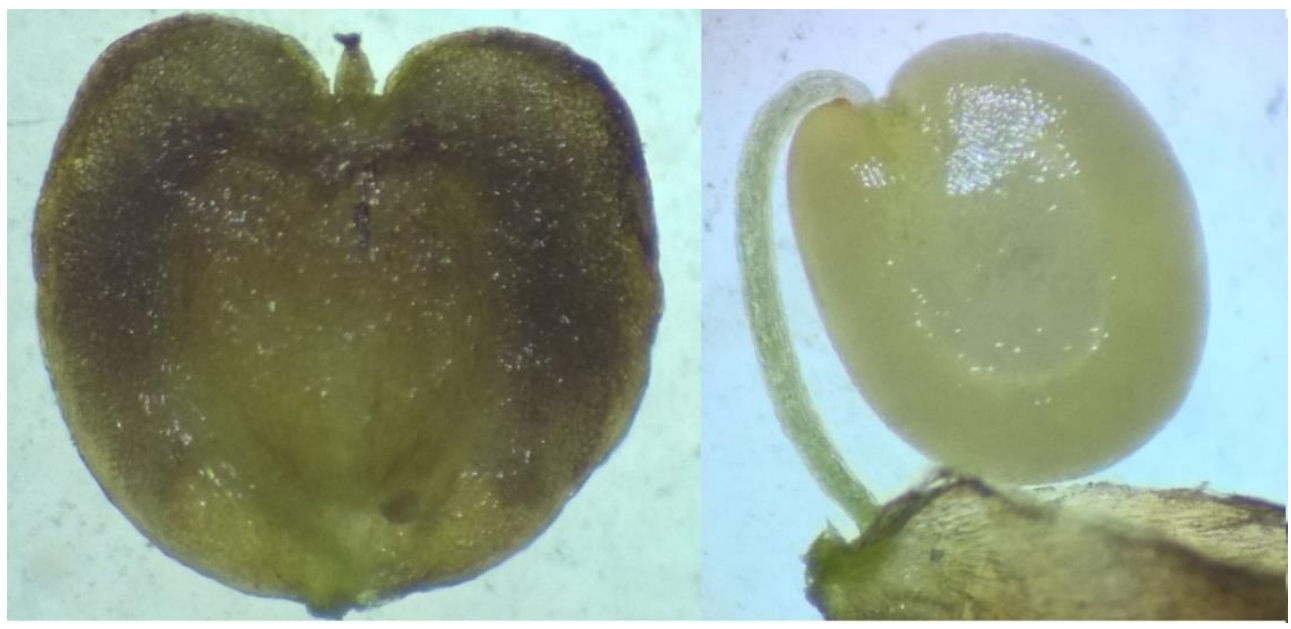

Şekil 4. Meyve (solda) ve tohum (sağda).

Herbaryum örnek numaraları: Y. Güzel-810, Y. Güzel-811. Örnekler Mustafa Kemal Üniversitesi Biyoloji Bölümü (MKÜ) ve Ankara Üniversitesi (ANK) herbaryumlarında saklanmıştır.

Habitat: Akarsu yatakları, nemli habitatlar, tarla kenarları.

Popülasyonların koordinatları aşağıda verilmiştir. Harita üzerindeki konumları Şekil 5'te gösterilmiştir (Anonymous 2016c):

$36^{\circ} 10^{\prime} 27.3^{\prime \prime} \mathrm{N} 36^{\circ} 07^{\prime} 56.0^{\prime \prime} \mathrm{E}$

$36^{\circ} 09^{\prime} 44.3^{\prime \prime} \mathrm{N} 36^{\circ} 066^{\prime} 56.6^{\prime \prime} \mathrm{E}$

$36^{\circ} 08^{\prime} 47.3^{\prime \prime} \mathrm{N} 36^{\circ} 05^{\prime} 55.9^{\prime \prime} \mathrm{E}$ 


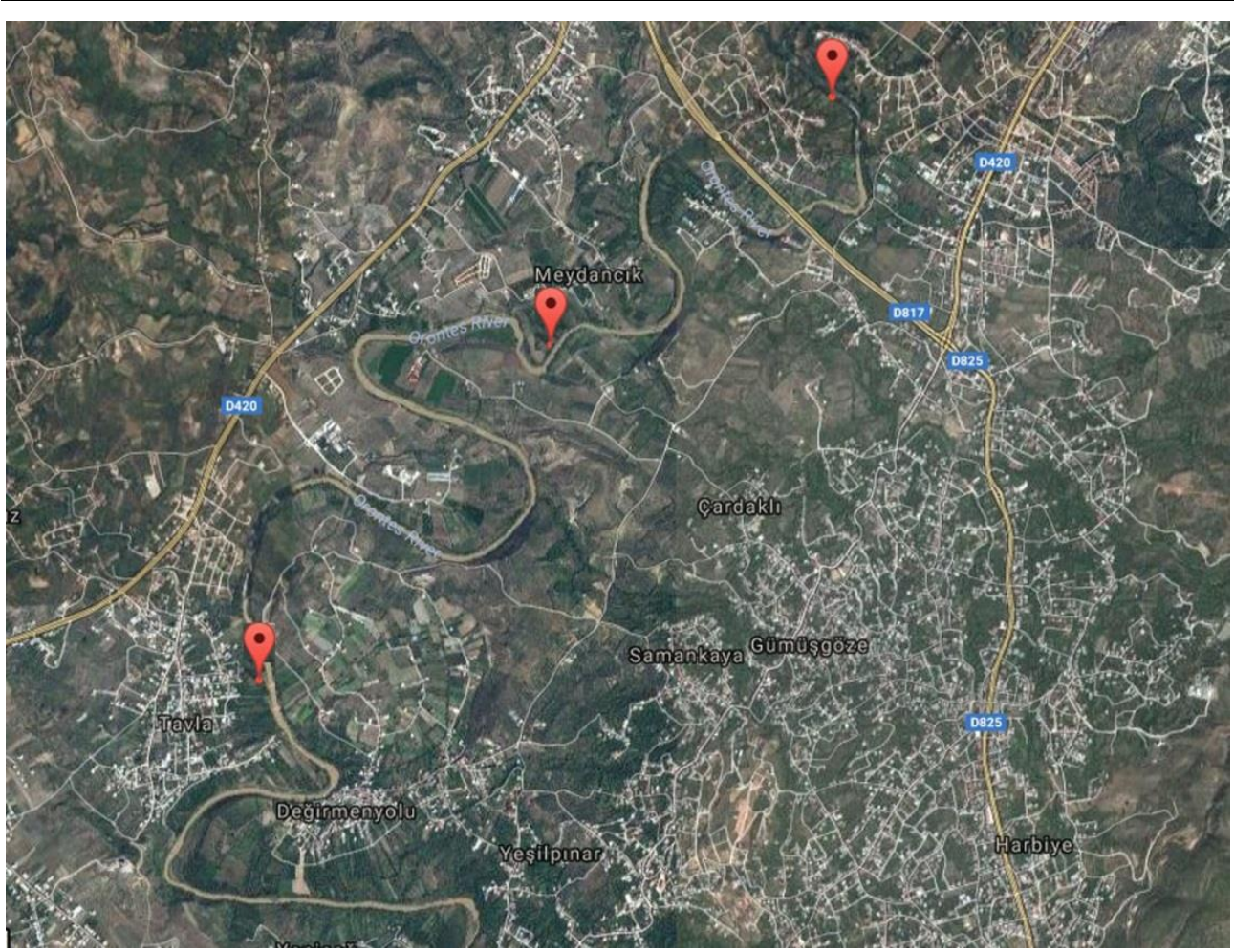

Şekil 5. Popülasyonların harita üzerindeki konumları.

\section{TARTIŞMA VE KANI}

Hatay'da Asi nehri yatağında tespit ettiğimiz A. sessilis popülasyonlarına dayanarak bu türün Türkiye'ye giriş yapmış olduğunu söyleyebiliriz. Ürdün ve İsrail gibi yakın ülkelerde kaydı bulunduğundan ayrıca, tohum yayma stratejisi olarak akarsuları kullanan bir tür olduğundan, Asi nehri ve diğer karasal su sistemleri yoluyla gelmiş olması kuvvetle muhtemeldir. Çeşitli Alternanthera türlerinin kültivarları akvaryumculukta dekoratif bitki olarak kullanılmaktaysa da A. sessilis'in doğal formunun bu amaçla kullanıldığına dair bir veriye rastlanılmamıştır. Yine de, cinsin bu tip yetiştiricilik faaliyetlerinden doğaya kaçabileceği ve istilacı karakteri sayesinde rahatlıkla ortama adapte olup yayılabileceği düşünülerek türlerinin satışına kısıtlamalar getirilmesi yerinde bir önlem olacaktır.

Rastladığımız popülasyonlar, Asi nehrinin tarım alanlarına yakın geçtiği bölgelerde, nehrin kıyılarında ya da nehir-tarla sınırında yer almaktadır. Suya yarı batık bireyler olduğu gibi, tarla sınırında bulunan bireyler de gözlenmiştir. Bu da bitkinin habitat seçiminde yüksek ekolojik toleransa sahip olduğunun göstergesidir. Popülasyon yoğunluğu ortalama $\mathrm{m}^{2}$ başına 3 bireydir. Bu yoğunluk değeri, çeşitli yayınlarda (Akça ve Işık 2016, Çoruh 2012), muhtelif yabancı otlar için verilen 
yoğunluk değerleri ile kıyaslandığında yüksek bir değerdir ve bitkinin popülasyon büyüklüğünü arttırabileceğinin diğer bir işaretidir.

EPPO (Anonymous 2016a), A. sessilis türünü istilac1 bitkiler arasında değerlendirse de henüz etki değerlendirme skalalarında yer vermemiştir, Akdeniz ülkelerine yayılmasının beklenen bir durum olduğu belirtilerek, takip edilmesi önerilmiştir. Cinsin diğer bir türü olan A. phyloxeroides'in EPPO karantina listesinde olduğunu göz önünde bulundurarak, ileride bir ekolojik risk oluşturma potansiyeli bakımından A. sessilis popülasyonlarının arazideki durumlarını takip etmek bundan sonraki öncelikli hedef olacaktır.

\section{TEŞEKKÜR}

Bitkiye ilk defa rastlayıp fotoğraflayan ve bu makale için Şekil 1'deki fotoğrafları ve Şekil 2'deki sessil çiçek durumu fotoğrafını paylaşan Dr. Ali Atahan'a içtenlikle teşekkür ederim.

\section{KAYNAKLAR}

Akça A. ve Işık D. 2016. Kayseri İli Şeker Pancarı (Beta vulgaris L.) Ekiliş Alanlarında Bulunan Yabancı Otların Tespiti. Bitki Koruma Bülteni, 56(1), 115-124.

Anonymous 2005. GISD, Global Invasive Species Database Alternanthera sessilis. http://issg.org/database/species/ecology.asp?si=767\&fr=1\&sts=tss\&lang=EN (Erişim tarihi: 2 Ekim 2016)

Anonymous 2015. CABI (Invasive Species Compendium, Alternanthera sessilis, original text by Rojas-Sandoval \& Acevedo-Rodríguez) In: Invasive Species Compendium. Wallingford, UK: CAB International. http://www.cabi.org/isc/datasheet/4404 (Erişim tarihi: 2 Ekim 2016)

Anonymous 2016a. EPPO, European and Mediterranean Plant Protection Organization, https://gd.eppo.int/reporting/article-358 (Erişim tarihi: 2 Ekim 2016)

Anonymous 2016b. eFloras, Published on the Internet http://www.efloras.org/florataxon.aspx?flora_id=5\&taxon_id=101216 [erişim: Ağustos 2016] Missouri Botanical Garden, St. Louis, MO \& Harvard University Herbaria, Cambridge, MA. (Erişim tarihi: 29 Eylül 2016)

Anonymous 2016c. Google Maps. Map of Hatay [online]. Google. Available from: https://www.google.com.tr/maps/place/36\%C2\%B010'27.3\%22N+36\%C2\%B007'5 6.0\%22E/@36.17425,36.1300335,17z/data=!3m1!4b1!4m5!3m4!1s0x0:0x0!8m2!3d 36.17425!4d36.1322222 [Erişim tarihi: 4 Eylül 2016].

Çoruh İ. 2012. Erzurum İli Fiğ (Vicia sp.) Ekim Alanlarında Görülen Yabancı Otlar, Yoğunlukları ve Rastlama Sıklıkları. Bitki Koruma Bülteni, 52(3), 261-272.

De Candolle A.P. 1813. Catalogus Plantarum Horti Botanici Monspeliensis, 77, http://bibdigital.rjb.csic.es/ing/Libro.php?Libro=932 (Erişim tarihi: 29 Eylül 2016) 
Gunasekera L. 2008. Sessile joyweed (Alternanthera sessilis): a popular leafy vegetable in South East Asia but federal noxious weed in USA. In: Proceedings of the 16th Australian Weeds Conference, Cairns Convention Centre, North Queensland, Australia, 18-22 May 2008, pp. 347-348.

Henao C.A.A. 2009. Neotropical Amaranthaceae. In: Milliken W., Klitgård B. and Baracat A. (eds), Neotropikey - Interactive key and information resources for flowering plants of the Neotropics. http://www.kew.org/science/tropamerica/neotropikey/families/Amaranthaceae.htm

Iamonico D. and Sánchez-Del Pino I. 2016. Taxonomic Revision of the Genus Alternanthera (Amaranthaceae) in Italy. Plant Biosystems, 150(2), 333-342.

$\begin{array}{lllll}\text { Linné } & \text { C. } & \text { 1753. } & \text { Species } & \text { Plantarum, }\end{array}$ http://www.biodiversitylibrary.org/item/13829\#page/237/mode/1up (Erişim tarihi: 29 Eylül 2016)

Tanveer A., Khaliq A. and Siddiqui M.H. 2013. A Review on Genus Alternanthera weeds implications. Pakistan Journal of Weed Science Research, 19(1), 53-58.

Odum E.P. 1971. Fundamentals of ecology. W. B. Saunders Company, Philadelphia, London, Toronto, $574 \mathrm{p}$.

Önen H. 2015. İstilacı Yabancı Türler ve İstila Süreçleri, Önen H. (Ed.), Türkiye İstilacı Bitkiler Kataloğu, Ezgi Ofset Matbaacılık, Ankara, 532 s.

Önen H., Farooq S. ve Özaslan C. 2015. Erken Tanı, Takip ve Bilgi Sistemi, Önen H. (Ed.) Türkiye İstilacı Bitkiler Kataloğu, Ezgi Ofset Matbaacılık, Ankara, 532 s. 